\title{
ATRIBUTOS FÍSICOS E PRODUTIVIDADE DE CULTURAS EM UM LATOSSOLO VERMELHO ARGILOSO SOB DIFERENTES SISTEMAS DE MANEJ $0^{(1)}$
}

\author{
Deonir Secco(2), Clovis Orlando Da $\operatorname{Ros}^{(3)}$, J ana Koefender \\ $\operatorname{Secco}^{(4)} \&$ J ackson Ernani Fiorin ${ }^{(5)}$
}

\begin{abstract}
RESUMO
Este trabalho foi realizado de 1994 a 1998 em área experimental da Universidade de Cruz Alta - UNICRUZ, com o objetivo de avaliar a densidade do solo, o espaço poroso (porosidade total, macro e microporosidade) e a produtividade das culturas da soja, trigo e milho em um Latossolo Vermelho distrófico típico sob cinco sistemas de manejo. $O$ delineamento experimental utilizado foi o de blocos ao acaso com quatro repetições. Os sistemas de manejo do solo utilizados foram: (a) plantio direto contínuo (PDC); (b) plantio direto com escarificação a cada três anos (PDSD); (c) plantio direto no verão com escarificação no outono/inverno (PDV); (d) preparo conservacionista: escarificador mais grade niveladora (PCEG), e (e) plantio convencional: arado de discos mais grade niveladora (PCAG). As amostras de solo foram coletadas em dois pontos por parcela nas profundidades de 0,0-0,07; 0,07-0,14 e 0,14-0,21 m. A densidade do solo, nas três profundidades avaliadas, apresentou valores superiores nos tratamentos com menor mobilização do solo (PDC e PDSD), enquanto a porosidade total ea macroporosidade apresentaram comportamento inverso. À exceção do PDV, os valores de densidade, porosidade total e volume de macroporos nos demais sistemas de manejo do solo, nos três anos consecutivos e nas três profundidades avaliadas, permaneceram praticamente constantes, não indicando tendência de adensamento no tempo. As produtividades das culturas da soja e milho não diferiram significativamente entre os sistemas de manejo utilizados, demonstrando que diferenças no estado estrutural do solo
\end{abstract}

\footnotetext{
(1) Recebido para publicação em junho de 2003 e aprovado em março de 2005.

(2) Professor Assistente do Centro de Ciências Exatas e Tecnológicas, Universidade Estadual do Oeste do Paraná - UNIOESTE. CEP 85819-110 Cascavel (PR). E-mail: deonir@unioeste.br

(3) Professor do Curso de Agronomia, Universidade de Cruz das Almas - UNICRUZ. CEP 98015-130 Cruz Alta (RS). E-mail: daros@unicruz.edu.br

(4) Doutoranda do Programa de Pós-Graduação em Agronomia, Universidade Federal de Santa Maria - UFSM. CEP 98010-470 Cruz Alta (RS). E-mail: janask@bol.com.br

(5) Doutorando do Programa de Pós-Graduação em Ciência do Solo, UFSM. E-mail: jfiorin@ @fundacep.comnet.com.br
} 
não comprometeram a produtividade dessas culturas. A cultura do trigo mostrouse sensível ao estado estrutural do solo, com os sistemas de manejo do solo com maior mobilização (PCAG) proporcionando condições mais adequadas a esta cultura. Os resultados encontrados indicaram que a mobilização do solo todo ano ou a cada três anos nas áreas cultivadas sob sistema plantio direto não alterou significativamente a produção das culturas e os atributos físicos avaliados.

Termos de indexação: porosidade, densidade do solo, plantio direto, produtividade soja, trigo e milho.

\title{
SUMMARY: CROP YIELD AND PHYSICAL ATTRIBUTES OF A CLAYEY OXISOL UNDER DIFFERENT MANAGEMENT SYSTEMS
}

\begin{abstract}
This study was carried out from 1994 to 1998 in the Agronomy experimental area at the University of Cruz Alta - UNICRUZ, Cruz Alta, State of Rio Grande do Sul, Brazil to eval uatethe influence of five soil management systems on bulk density, porous space (total porosity, macro and mi croporosity) of an clayey Rhodic Hapludox, as well as their effect on soybean, wheat and corn yield. Theexperiment had a completely randomized block design with four replications. The following management systems were used: (1) continuous notillage-PDC; (2) no-tillage with chiseling every three years-PDSD; (3) summer no-tillage with autumn/ winter chiseling -PDV; (4) reduced tillage systems: chiseling plus harrow disking-PCEG; and, (5) conventional tillage: disk plowing plus harrow disking-PCAG. Two samples were collected in each experimental unit at depths of 0.0-0.07, 0.07-0.14 and 0.14$0.21 \mathrm{~m}$. In thethreestudied depths thesoil bulk density was higher for thetreatments with less soil mobilizati on (PDC and PDSD), whilethetotal porosity and macroporosity showed an opposite behavior. With exception of PDV, the bulk density values, total porosity and macroporosity were practi cal ly constant in theother management systems during thethree consecutive years at the three studied depths, indicating no soil compaction tendency over time. The yield of soybean and corn did not differ significantly among the management systems, demonstrating that for thesecrops thesoil structuredid not affect theyield. Wheat was sensitiveto thestructural state of the soil sincethemanagement systems with most soil mobilization (PCGA) provided moreappropriateconditions. Theresults evidenced no need to mobilize the soil each year or every three years in the areas operated under no tillage systems.
\end{abstract}

Index terms: porosity, bulk density, no-tillage, soybean, wheat, corn.

\section{INTRODUÇÃO}

Os Latossolos pertencem a uma classe de solos de suma importância, tendo em vista oseu potencial de produção e a extensão de área que ocupam no planalto riograndense. Estabelecer sistemas de manejo conservacionistas que objetivam a sustentabilidade desses solos é de grande interesse para a região. Nesse sentido, o sistema plantio direto, quando conduzido adequadamente, pode possibilitar a recuperação e a preservação da estrutura do solo.

No sistema plantio direto, o solo é submetido a menor tráfego, porém, não é revolvido, tendendo ao adensamento superficial do solo. O adensamento tem sido verificado pelo aumento da densidade do sol o e da microporosidade, da diminuição da porosidade total e, principalmente, da macroporosidade (Sidiras et al., 1984), sendo estas variações mais freqüentes em solos de textura argilosa (Raghavan et al., 1977). Em trabal ho mais recente, Stone \& Silveira (2001) também afirmaram que o sistema plantio direto proporcionava maiores valores de densidade e microporosidade, e, em conseqüência, menor porosidade total e macroporosidade. Os mesmos autores afirmam que a densidade do solo influiu em diversos atributos do sol o que regulam o crescimento e o desenvolvimento das plantas, a saber: a aeração, a condutividade de água, o calor, a disponibilidade de nutrientes e a resistência à penetração do solo. Fernandez et al. (1995) verificaram completa inibição do crescimento radicular da soja, em LatossoloVermelho-E scurotextura média, quando a densidade do solo apresentou valor a partir de $1,52 \mathrm{Mg} \mathrm{m}^{-3}$. Por outro lado, Tavares Filho et al. 
(2001) concluíram que o plantio direto apresentou mel hor es condições de continuidade estrutural para o desenvolvimento radicular do milho, quando comparado com o sistema convencional.

Com relação à porosidade de aeração do solo, ela se torna limitante para o desenvolvimento da maioria das plantas quando for menor que 10-15\% (Stolzy, 1974), podendo variar com a espécie vegetal (Taylor, 1974). Independentemente da espécie vegetal, a maximização da produção é alcançada quando há disponibilidade adequada de água, nutrientes e oxigênio, queé, di reta ou indir retamente, influenciada pela estrutura do solo.

Alguns atributos físicos do solo, como densidade e espaço poroso, podem ser utilizados como indicadores da qualidade do solo de acordo com o manejo a que o solo está sendo submetido. Uma contínua aval iação, notempo, destes atri butos físicos do sol o permite monitorar a eficiência ou não destes sistemas de manejo do solo quando se objetiva estabilidade estrutural.

O objetivo deste estudo foi verificar a influência de cinco sistemas de manejo, ao longo de três anos consecutivos, nos atributos físicos de um Latossolo Vermel ho distrófico e na produtividade das culturas da soja, trigo e milho.

\section{MATERIAL E MÉTODOS}

O experimento foi realizado por três anos em área experimental da Universidade de Cruz Alta UNICRUZ, no município de Cruz Alta (RS), em convênio com F undação Centro de Experimentação e Pesquisa Fecotrigo (FUNDACEP FECOTRIGO). O solo é classificado como Latossolo Vermel ho distrófico típico textura argilosa (E mbrapa, 1999). Antes da instalação do experimento, a área vinha sendo cultivada há dois anos sob o sistema plantio direto com as culturas da soja e do feijoei ro no verão e aveia no inverno. O histórico de cultivo e os sistemas de rotação de culturas utilizados na área experimental, no inverno e no verão estão indicados no quadro 1. A área apresenta uma declividade média inferior a $2 \%$. Alguns atributos físicos do solo, para caracterizar a área experimental, encontram-se no quadro 2.

O clima, segundo a classificação de Köeppen, é subtropical, tipo cfa $2 a$, com chuvas distribuídas uniformemente durante o ano, num total de $1.727 \mathrm{~mm}$. O mês mais quente do anoéjaneiro, com a máxima de $30^{\circ} \mathrm{C}$, e, em julho, ocorre o maior frio, com a mínima normal de $8,6^{\circ} \mathrm{C}$. No quadro 3 , encontra-se a distribuição das precipitações pluviométricas ocorridas durante os anos de 1994 a 1998 no município de Cruz Alta (RS).

O delineamento experimental utilizado foi o de blocos ao acaso com quatro repeti ções. Cada unidade experimental mediu $10 \times 30 \mathrm{~m}$. Os tratamentos que caracterizaram os sistemas de manejo do sol o foram: (a) plantio direto contínuo (PDC); (b) plantio direto com escarificação a cada três anos (PDSD); (c) plantio direto no verão com escarificação no outono/inverno (PDV); (d) preparo conservacionista: escarificador mais grade niveladora (PCEG), e (e) plantio convencional: arado de disco mais grade niveladora (PCAG). Iniciou-se o experimento em 1994,

\section{Quadro 1. Histórico de cultivos e sistemas de rotação} de culturas utilizados na área experimental

\begin{tabular}{lll}
\hline Ano & Inverno & \multicolumn{1}{c}{ Verão } \\
\hline 1992 & Aveia & Soja \\
1993 & Aveia & Feijão \\
1994 & Aveia & Soja \\
1995 & Aveia & Milho \\
1996 & Trigo & Soja \\
1997 & Aveia & Milho(1)/ nabo
\end{tabular}

(1) Foi realizada a semeadura do milho no sistema plantio direto em todos os tratamentos.

\section{Quadro 2. Atributos físicos do solo da área experimental antes da instalação do experimento}

\begin{tabular}{|c|c|c|c|c|}
\hline \multirow{2}{*}{ Atributo físico } & \multicolumn{4}{|c|}{ Profundidade (m) } \\
\hline & $0,0-0,07$ & $0,07-0,14$ & $0,14-0,21$ & $0,0-0,20$ \\
\hline Densidade do solo $\left(\mathrm{Mg} \mathrm{m}^{-3}\right)$ & 1,13 & 1,28 & 1,30 & $*$ \\
\hline Porosidade total ( $\left.\mathrm{dm}^{3} \mathrm{dm}^{-3}\right)$ & 0,57 & 0,51 & 0,50 & $*$ \\
\hline Macroporosidade $\left(\mathrm{dm}^{3} \mathrm{dm}^{-3}\right)$ & 0,28 & 0,20 & 0,18 & $*$ \\
\hline Microporosidade $\left(\mathrm{dm}^{3} \mathrm{dm}^{-3}\right)$ & 0,29 & 0,31 & 0,32 & $*$ \\
\hline Argila $\left(g_{k g}{ }^{-1}\right)$ & $*$ & $*$ & $*$ & 477 \\
\hline Areia total $\left(\mathrm{g} \mathrm{kg}^{-1}\right)$ & $*$ & $*$ & $*$ & 350 \\
\hline Silte $\left(\mathrm{g} \mathrm{kg}^{-1}\right)$ & $*$ & $*$ & $*$ & 173 \\
\hline Densidade de partícula $\left(\mathrm{Mg} \mathrm{m}^{-3}\right)$ & $*$ & $*$ & $*$ & 2,62 \\
\hline
\end{tabular}

* Não determinado. 
ocorrendo o monitoramento dos atributos físicos do solo após a colheita da cultura de verão nos anos 1995, 1996 e 1997. O tratamento PDSD sofreu escarificação somente no segundo ano (abril 1995). Os tratamentos PDSD e PDV não sofreram gradagem niveladora após a escarificação. $\mathrm{Na}$ escarificação, utilizou-se escarificador model ojumbo que continha cinco hastes espaçadas em 0,25 m e foi regulado para mobilizar o soloatéà profundidade de $0,20 \mathrm{~m}$. A semeadora-adubadora utilizada era equi pada com sulcador tipo dupl os discos defasados, para deposição de sementes, e sulcador tipo facão, para deposição do adubo nas culturas de verão; nas culturas de inverno, a semeadora era equipada somente com sulcador tipo duplo disco defasado, ocorrendo a deposição do adubo e da semente em conjunto.

Nos três anos de estudo (1995, 1996 e 1997), foram avaliados a densidade e o espaço poroso do sol o nos diferentes sistemas de manejo do solo. A densidade do sol o foi avaliada retirando-se duas subamostras por parcela por meio de anéis volumétricos de 0,03 m de altura e 0,085 m de diâmetro, nas profundidades de $0,0-0,07 ; 0,07-0,14$ e 0,14-0,21 m. A densidade de partícula foi determinada pelo método do balão volumétrico com álcool. O espaço poroso do solo (porosidade total, macro e microporosidade) foi determinado nas mesmas profundidades. Para a microporosidade foram coletadas amostras indeformadas de sol o (torrões) e, nolaboratório, estas amostras foram parafinadas e saturadas com água, sendo considerada, como microporosidade, o conteúdo vol umétrico de água equilibrada na mesa de tensão a $60 \mathrm{~cm}$ de coluna de água. A porosidade total foi calculada por meio da equação: PT $=1$ - Ds/ $\mathrm{Dp}$, em que PT = Porosidade total, em $\mathrm{dm}^{3} \mathrm{dm}^{-3}$; $\mathrm{Ds}=$ Densidade do solo, em $\mathrm{Mg} \mathrm{m}^{-3} ; \mathrm{Dp}=$ Densidade de partícula, em $\mathrm{Mg} \mathrm{m}^{-3}$, e a macroporosidade foi cal culada por diferença entre a porosidade total ea microporosidade.

O rendimento de grãos das culturas foi avaliado tomando-se al eatoriamente duas subamostras por parcela, de quatro fileiras com cinco metros de comprimento para todas as culturas. A análise estatística dos resultados foi realizada por meio da análise da variância, por profundidade para os atributos físicos, e as médias de tratamentos comparadas pelo teste de Duncan a $5 \%$ de significância.

\section{RESULTADOS E DISCUSSÃO}

A densidade do solo, nas três profundidades enos três anos analisados, apresentou, de maneira geral, valores superiores nos tratamentos que sofreram menor mobilização do solo (PDC e PDSD), exceto nas profundidades de 0,0-0,07 e de 0,07-0,14 m, no ano de 1996, quando não houve diferença estatística significativa entre os sistemas de manejo do solo (Quadro 4). Estes resultados concordam com os resultados encontrados por Sidiras et al. (1984) e Stone \& Silveira (2001), os quais verificaram que os valores de densidade mostraram-se superiores no sistema plantio direto em relação ao sistema convencional.

Outro aspecto a ser considerado é o de que os valores de densidade do solo nesses sistemas de manejo, nos três anos consecutivos e nas três profundidades, permaneceram praticamente constantes, não indicando tendência de adensamento no tempo, à exceção do tratamento PDV, queapresentou tendência deadensamento com o tempo. Essa tendência de adensamento no PDV pode ser verificada pelo aumento da densidade e redução do espaço poroso do solo (porosi dade total e macroporosidade, quadros 5 e 6 , respectivamente). Nos tratamentos que sofreram menor mobilização (PDC e PDSD), nas três profundidades avaliadas e nos três anos, os valores da porosidade total do solo foram inferiores aos dos demais sistemas de manejo do solo (Quadro 5). J á nos tratamentos com maior mobilização, a porosidade total foi maior, o que já era esperado, pois a mobilização aumenta o volume do espaço poroso do solo.

Os valores de macroporosidade apresentaram comportamento semelhante aos valores de porosidade total, uma vez que nos tratamentos que sofreram menor mobilização (PDC ePDSD), nas três profundidades avaliadas e nos três anos, os valores da macroporosidade do solo foram inferiores em

Quadro 3. Distribuição das preci pitações pluviométricas $(\mathrm{mm})$ ocorridas durante os anos de 1994 a 1998 no município de Cruz Alta (RS)

\begin{tabular}{rrrrrrrrrrrrrr}
\hline Ano & J aneiro Fevereiro & Março & Abril & Maio J unho J ulho & Agosto Setembro Outubro Novembro Dezembro \\
\hline 1994 & 69 & 275 & 102 & 262 & 167 & 190 & 266 & 85 & 157 & 265 & 189 \\
1995 & 170 & 84 & 126 & 32 & 32 & 113 & 132 & 40 & 106 & 163 & 33 & 167 \\
1996 & 320 & 207 & 101 & 125 & 70 & 119 & 99 & 175 & 50 & 197 & 77 \\
1997 & 201 & 103 & 56 & 66 & 113 & 165 & 66 & 132 & 123 & 510 & 349 & 275 \\
1998 & 226 & 380 & 115 & 300 & 106 & 125 & 123 & 182 & 161 & 154 & 25 & 137 \\
\hline
\end{tabular}


Quadro 4. Densidade de um Latossolo Vermelho distrófico, em três anos consecutivos, sob diferentes sistemas de manejo

\begin{tabular}{llll}
\hline & \multicolumn{3}{c}{ Ano } \\
\cline { 2 - 4 } Sistema de manejo(1) & 1995 & 1996 & 1997 \\
\hline
\end{tabular}

$\mathrm{Mg} \mathrm{m}^{-3}$

Profundidade de 0,00-0,07 m

$\begin{array}{llll}\text { PDC } & 1,24 \mathrm{a}^{(2)} & 1,21 & 1,19 \mathrm{a} \\ \text { PDSD } & 1,14 \mathrm{ab} & 1,22 & 1,20 \mathrm{a} \\ \text { PDV } & 1,08 \mathrm{~b} & 1,18 & 1,27 \mathrm{a} \\ \text { PCEG } & 1,09 \mathrm{~b} & 1,20 & 1,07 \mathrm{~b} \\ \text { PCAG } & 1,12 \mathrm{~b} & 1,21 & 1,08 \mathrm{~b} \\ \text { F (manejo) } & 3,29 * & 0,24^{\text {ns }} & 6,88^{*} \\ \text { C.V. (\%) } & 6,08 & 4,46 & 5,44\end{array}$

Profundidade de 0,07-0,14 m

$\begin{array}{llll}\text { PDC } & 1,31 \mathrm{a} & 1,31 & 1,32 \mathrm{a} \\ \text { PDSD } & 1,32 \mathrm{a} & 1,32 & 1,30 \mathrm{a} \\ \text { PDV } & 1,19 \mathrm{~b} & 1,25 & 1,32 \mathrm{a} \\ \text { PCEG } & 1,23 \mathrm{~b} & 1,25 & 1,15 \mathrm{~b} \\ \text { PCAG } & 1,18 \mathrm{~b} & 1,29 & 1,24 \mathrm{~b} \\ \text { F (manejo) } & 8,36^{*} & 0,74 \mathrm{~ns} & 5,11^{*} \\ \text { C.V. (\%) } & 3,71 & 5,87 & 5,03\end{array}$

Profundidade de 0,14-0,21 m

$\begin{array}{llll}\text { PDC } & 1,29 \mathrm{ab} & 1,33 \mathrm{a} & 1,32 \mathrm{a} \\ \text { PDSD } & 1,32 \mathrm{a} & 1,30 \mathrm{a} & 1,31 \mathrm{a} \\ \text { PDV } & 1,19 \mathrm{bc} & 1,18 \mathrm{bc} & 1,24 \mathrm{ab} \\ \text { PCEG } & 1,18 \mathrm{bc} & 1,27 \mathrm{ab} & 1,15 \mathrm{~b} \\ \text { PCAG } & 1,17 \mathrm{c} & 1,16 \mathrm{c} & 1,30 \mathrm{a} \\ \text { F (manejo) } & 4,26^{*} & 5,53^{*} & 3,72^{*} \\ \text { C.V. (\%) } & 5,60 & 4,97 & 6,15\end{array}$

(1) PDC: plantio direto contínuo; PDSD: plantio direto e escarificação de acordo com a necessidade (sistema dinâmico): PDV: Plantio direto no verão com escarificação no outono/inverno; PCEG: plantio convencional:escarificador mais grade niveladora; PCAG: plantio convencional: arado de discos mais grade niveladora. ${ }^{(2)}$ Médias com letras distintas na col una e por profundidade diferem pel o teste de Duncan a $5 \%$. ${ }^{\text {ns }}$ Teste $F$ nãosignificativo a $5 \%$ de significância. *Teste $\mathrm{F}$ significativo a $5 \%$ de significância.

relação aos dos demais sistemas de manejo do solo (Quadro 6). J á os tratamentos com maior mobilização apresentaram maiores valores de macroporosidade.

A microporosidade do solo apresentou comportamento diferenciado nas três profundidades e nos três anos analisados (Quadro 7). No ano de 1995, ocorreu diferença significativa apenas na profundidade de 0,07-0,14 m, onde o tratamento PDC diferiu apenas do tratamento PCAG. No ano de 1996, apenas na profundidade de 0,14-0,21 m
Quadro 5. Porosidade total de um Latossolo Vermelho distrófico, em três anos consecutivos, sob diferentes sistemas de manejo

\begin{tabular}{|c|c|c|c|}
\hline \multirow{2}{*}{ Sistema de manejo(1) } & \multicolumn{3}{|c|}{ Ano } \\
\hline & 1995 & 1996 & 1997 \\
\hline & \multicolumn{3}{|c|}{$-\mathrm{dm}^{3} \mathrm{dm}^{-3}$} \\
\hline & \multicolumn{3}{|c|}{ Profundidade de $0,00-0,07 \mathrm{~m}$} \\
\hline PDC & $0,52 b^{(2)}$ & 0,54 & $0,54 \mathrm{~b}$ \\
\hline PDSD & $0,56 \mathrm{ab}$ & 0,53 & $0,54 \mathrm{~b}$ \\
\hline PDV & $0,59 \mathrm{a}$ & 0,56 & $0,52 \mathrm{~b}$ \\
\hline PCEG & $0,59 \mathrm{a}$ & 0,54 & $0,59 \mathrm{a}$ \\
\hline PCAG & $0,57 \mathrm{a}$ & 0,54 & $0,58 \mathrm{a}$ \\
\hline $\mathrm{F}$ (manejo) & $3,29 *$ & $0,24^{\mathrm{ns}}$ & $6,88^{*}$ \\
\hline \multirow[t]{2}{*}{ C.V. $(\%)$} & 4,64 & 4,12 & 4,35 \\
\hline & \multicolumn{3}{|c|}{ Profundidade de $0,07-0,14 \mathrm{~m}$} \\
\hline PDC & $0,50 \mathrm{~b}$ & 0,50 & $0,49 \mathrm{~b}$ \\
\hline PDSD & $0,50 \mathrm{~b}$ & 0,49 & $0,50 \mathrm{~b}$ \\
\hline PDV & $0,55 \mathrm{a}$ & 0,52 & $0,49 \mathrm{~b}$ \\
\hline PCEG & $0,53 \mathrm{a}$ & 0,52 & $0,50 \mathrm{a}$ \\
\hline PCAG & $0,55 \mathrm{a}$ & 0,51 & $0,53 \mathrm{ab}$ \\
\hline F (manejo) & $8,35^{*}$ & $0,73^{\mathrm{ns}}$ & $5,11 *$ \\
\hline \multirow[t]{2}{*}{ C.V. $(\%)$} & 3,39 & 5,66 & 4,71 \\
\hline & \multicolumn{3}{|c|}{ Profundidade de $0,14-0,21 \mathrm{~m}$} \\
\hline PDC & $0,50 \mathrm{bc}$ & $0,49 \mathrm{~b}$ & $0,50 \mathrm{~b}$ \\
\hline PDSD & $0,50 \mathrm{c}$ & $0,50 \mathrm{~b}$ & $0,50 \mathrm{~b}$ \\
\hline PDV & $0,54 \mathrm{ab}$ & $0,54 \mathrm{a}$ & $0,53 \mathrm{ab}$ \\
\hline PCEG & $0,54 \mathrm{ab}$ & $0,52 \mathrm{~b}$ & $0,56 \mathrm{a}$ \\
\hline PCAG & $0,56 \mathrm{a}$ & $0,56 \mathrm{a}$ & $0,49 \mathrm{~b}$ \\
\hline F (manejo) & $4,25 *$ & $5,53 *$ & $3,72 *$ \\
\hline C.V. (\%) & 4,96 & 4,53 & 5,77 \\
\hline
\end{tabular}

(1) PDC: plantio direto contínuo; PDSD: plantio direto e escarificação de acordo com a necessidade (sistema dinâmico); PDV: Plantio direto no verão com escarificação no outono/inverno; PCEG: plantio convencional:escarificador mais grade niveladora; PCAG: plantio convencional: arado de discos mais grade niveladora. ${ }^{(2)}$ Médias com letras distintas na coluna e por

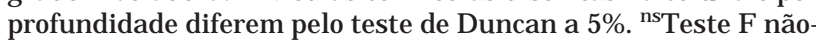
significativo a $5 \%$ de significância. *Teste $\mathrm{F}$ significativo a $5 \%$ de significância.

ocorreu diferença significativa, onde o tratamento PDC diferiu dos tratamentos PDV e PCAG. Já no ano de 1997, as diferenças ocorreram nas três profundidades, Na profundidade de 0,0-0,07 $\mathrm{m}$, os tratamentos PDSD ePDV diferiram dos tratamentos PCEG ePCAG; na profundidade de 0,07-0,14 m, os tratamentos PDC, PDSD e PDV diferiram do tratamento PCEG e, na profundidade de 0,14$0,21 \mathrm{~m}$, houve diferença significativa apenas entre os tratamentos PDC (com maior volume de microporos) e o tratamento PCEG. Por meio da 
Quadro 6. Macroporosidade de um Latossolo Vermel ho distrófico, em três anos consecutivos, sob diferentes sistemas de manejo

\begin{tabular}{|c|c|c|c|}
\hline \multirow{2}{*}{ Sistema de manejo(1) } & \multicolumn{3}{|c|}{ Ano } \\
\hline & 1995 & 1996 & 1997 \\
\hline & \multicolumn{3}{|c|}{$\mathrm{dm}^{3} \mathrm{dm}^{-3}$} \\
\hline & \multicolumn{3}{|c|}{ Profundidade de $0,00-0,07 \mathrm{~m}$} \\
\hline PDC & $0,20 b^{(2)}$ & 0,22 & $0,24 \mathrm{~b}$ \\
\hline PDSD & $0,25 a b$ & 0,20 & $0,23 \mathrm{~b}$ \\
\hline PDV & $0,30 \mathrm{a}$ & 0,23 & $0,19 \mathrm{~b}$ \\
\hline PCEG & $0,31 \mathrm{a}$ & 0,24 & $0,32 \mathrm{a}$ \\
\hline PCAG & $0,29 a$ & 0,24 & 0,31 a \\
\hline F (manejo) & $3,38^{*}$ & $0,59^{\text {ns }}$ & $7,36^{*}$ \\
\hline \multirow[t]{2}{*}{ C.V. (\%) } & 17,4 & 18,5 & 16,0 \\
\hline & \multicolumn{3}{|c|}{ Profundidade de $0,07-0,14 \mathrm{~m}$} \\
\hline PDC & 0,16 bc & 0,16 & $0,16 b$ \\
\hline PDSD & $0,15 \mathrm{c}$ & 0,15 & $0,17 \mathrm{~b}$ \\
\hline PDV & $0,24 \mathrm{a}$ & 0,20 & $0,17 \mathrm{~b}$ \\
\hline PCEG & $0,21 a b$ & 0,20 & $0,27 a$ \\
\hline PCAG & $0,26 \mathrm{a}$ & 0,19 & $0,21 \mathrm{ab}$ \\
\hline$F$ (manejo) & $7,26^{*}$ & $0,88^{\mathrm{ns}}$ & $4,11^{*}$ \\
\hline \multirow[t]{2}{*}{ C.V. (\%) } & 17,5 & 25,7 & 21,9 \\
\hline & \multicolumn{3}{|c|}{ Profundidade de $0,14-0,21 \mathrm{~m}$} \\
\hline PDC & $0,16 \mathrm{bc}$ & $0,14 \mathrm{c}$ & $0,16 \mathrm{~b}$ \\
\hline PDSD & $0,15 \mathrm{c}$ & $0,16 \mathrm{bc}$ & $0,17 \mathrm{~b}$ \\
\hline PDV & $0,24 a b$ & $0,24 a b$ & $0,21 \mathrm{a}$ \\
\hline PCEG & $0,23 a b$ & $0,18 a b c$ & $0,27 a$ \\
\hline PCAG & $0,26 a$ & $0,26 a$ & $0,15 b$ \\
\hline F (manejo) & $3,68^{*}$ & $4,48^{*}$ & $3,31 *$ \\
\hline C.V. (\%) & 24,9 & 25,2 & 26,6 \\
\hline
\end{tabular}

(1) PDC: plantio direto contínuo; PDSD: plantio direto e escarificação de acordo com a necessidade (sistema dinâmico); PDV: Plantio direto no verão com escarificação no outono/inverno; PCEG: plantio convencional:escarificador mais grade niveladora; PCAG: plantio convencional: arado de discos mais grade niveladora. ${ }^{(2)}$ Médias com letras distintas na coluna e por

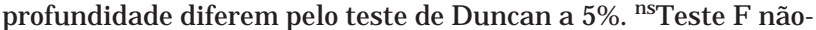
significativo a $5 \%$ de significância. *Teste $\mathrm{F}$ significativo a $5 \%$ de significância.

análise dos valores de mi croporosi dade nãoé possível identificar tendência de adensamento do solo com o tempo, nos diferentes sistemas de manejo estudados, a exemplo do que ocorreu com os valores de densidade e macroporosidade do solo.

Com relação à produtividade, verificou-se que, para as culturas da soja (safras 94/95 e96/97) emilho (safras 95/96 e97/98), nãohouve diferença estatística significativa entre os sistemas de manejo utilizados. I sso demonstra que o estado estrutural (densidade e espaço poroso do solo) não comprometeu a
Quadro 7. Microporosidade de um Latossolo Vermelho distrófico, em três anos consecutivos, sob diferentes sistemas de manejo

\begin{tabular}{llll}
\hline & \multicolumn{3}{c}{ Ano } \\
\cline { 2 - 4 } Sistema de manejo(1) & \multicolumn{3}{c}{$\mathbf{1 9 9 7}$} \\
\cline { 2 - 4 } & \multicolumn{3}{c}{$\mathrm{dm}^{3} \mathrm{dm}^{-3}$} \\
\cline { 2 - 4 } & \multicolumn{3}{c}{ Profundidade de $0,00-0,07 \mathrm{~m}$} \\
PDC & 0,32 & 0,32 & $0,30 \mathrm{ab}^{(2)}$ \\
PDSD & 0,31 & 0,33 & $0,31 \mathrm{a}$ \\
PDV & 0,29 & 0,23 & $0,33 \mathrm{a}$ \\
PCEG & 0,28 & 0,30 & $0,27 \mathrm{~b}$ \\
PCAG & 0,28 & 0,30 & $0,27 \mathrm{~b}$ \\
F (manejo) & $3,10 \mathrm{~ns}$ & $1,35 \mathrm{~ns}$ & $6,40^{*}$ \\
C.V. (\%) & 8,3 & 7,5 & 6,8 \\
& \multicolumn{3}{c}{} \\
PDC & Profundidade de $0,07-0,14 \mathrm{~m}$ \\
PDSD & 0,34 ab & 0,34 & $0,33 \mathrm{a}$ \\
PDV & $0,35 \mathrm{a}$ & 0,34 & $0,33 \mathrm{a}$ \\
PCEG & $0,31 \mathrm{bc}$ & 0,32 & $0,33 \mathrm{a}$ \\
PCAG & $0,32 \mathrm{abc}$ & 0,32 & $0,29 \mathrm{~b}$ \\
F (manejo) & $0,29 \mathrm{c}$ & 0,32 & $0,32 \mathrm{ab}$ \\
C.V. (\%) & $5,15^{*}$ & $1,15 \mathrm{~ns}$ & $2,66^{*}$ \\
& 6,17 & 6,16 & 6,22
\end{tabular}

Profundidade de $0,14-0,21 \mathrm{~m}$

$\begin{array}{llll}\text { PDC } & 0,34 & 0,35 \mathrm{a} & 0,34 \mathrm{a} \\ \text { PDSD } & 0,35 & 0,34 \mathrm{ab} & 0,33 \mathrm{ab} \\ \text { PDV } & 0,30 & 0,30 \mathrm{~b} & 0,32 \mathrm{ab} \\ \text { PCEG } & 0,31 & 0,34 \mathrm{ab} & 0,29 \mathrm{~b} \\ \text { PCAG } & 0,30 & 0,30 \mathrm{~b} & 0,34 \mathrm{a} \\ \text { F (manejo)0 } & 2,79 \mathrm{~ns} & 3,24^{*} & 2,58^{*} \\ \text { C.V. (\%) } & 8,59 & 8,42 & 6,93\end{array}$

(1) PDC: plantio direto contínuo; PDSD: plantio direto e escarificação de acordo com a necessidade (sistema dinâmico); PDV: Plantio direto no verão com escarificação no outono/inverno; PCEG: plantio convencional:escarificador mais grade niveladora; PCAG: plantio convencional: arado de discos mais grade niveladora. ${ }^{(2)}$ Médias com letras distintas na coluna e por profundidade diferem pelo teste de Duncan a $5 \%$. ${ }^{\text {ns }}$ Teste $\mathrm{F}$ nãosignificativo a $5 \%$ de significância. * Teste F significativo a $5 \%$ de significância.

produtividade, ou seja, as modificações ocorridas nesses atributos físicos, provocadas pelos sistemas de manejo do solo, nãoforam afetadas deforma suficiente para interferir na produtividade das culturas (Quadro 8).

A cultura dotrigo foi sensível ao estado estrutural do solo em relação às culturas da soja e do milho. O sistema de manejo do solo com maior mobilização (PCAG) proporcionou condições mais adequadas a esta cultura, tendo em vista queneste sistema de manejo do solo a produtividade diferiu significativamente 
Quadro 8. Produtividade de soja, milho, trigo e produção acumulada, considerando-se os sistemas de manejo do solo em um Latossolo Vermelho distrófico

\begin{tabular}{|c|c|c|c|c|c|c|c|}
\hline Sistema de manejo(1) & $\begin{array}{c}\text { Soja } \\
(94 / 95)\end{array}$ & $\begin{array}{l}\text { Milho } \\
(95 / 96)\end{array}$ & $\begin{array}{c}\text { Trigo } \\
\text { (96) }\end{array}$ & $\begin{array}{c}\text { Soja } \\
(96 / 97)\end{array}$ & $\begin{array}{l}\text { Milho } \\
(97 / 98)\end{array}$ & $\begin{array}{c}\text { Produção } \\
\text { acumulada }\end{array}$ & $\begin{array}{c}\text { Total } \\
\text { relativo }\end{array}$ \\
\hline & \multicolumn{6}{|c|}{ Mg ha-1 } & $\%$ \\
\hline $\begin{array}{l}\text { PDC } \\
\text { PDSD } \\
\text { PDV } \\
\text { PCEG } \\
\text { PCAG } \\
\text { F (manejo) }\end{array}$ & $\begin{array}{l}3,10 \\
2,98 \\
2,96 \\
3,19 \\
3,26 \\
1,79 \text { ns }\end{array}$ & $\begin{array}{l}5,86 \\
5,52 \\
5,33 \\
5,30 \\
4,65 \\
2,36 \text { ns }\end{array}$ & $\begin{array}{l}1,82 b^{(2)} \\
1,75 \mathrm{~b} \\
1,82 \mathrm{~b} \\
1,97 \mathrm{ab} \\
2,19 \mathrm{a} \\
5,74^{*}\end{array}$ & $\begin{array}{l}2,83 \\
2,71 \\
2,84 \\
2,73 \\
2,76 \\
0,49 \text { ns }\end{array}$ & $\begin{array}{l}5,94 \\
6,14 \\
6,09 \\
6,29 \\
6,72 \\
0,38 \mathrm{~ns}\end{array}$ & $\begin{array}{c}19,55 \\
19,10 \\
19,05 \\
19,48 \\
19,58 \\
0,15^{\text {ns }}\end{array}$ & $\begin{array}{c}99,8 \\
97,6 \\
97,3 \\
99,5 \\
100\end{array}$ \\
\hline C.V. (\%) & 6,32 & 10,85 & 7,84 & 6,26 & 15.45 & 7,37 & \\
\hline
\end{tabular}

(1) PDC: plantio direto contínuo; PDSD: plantio direto e escarificação de acordo com a necessidade (sistema dinâmico); PDV: Plantio direto no verão com escarificação no outono/inverno; PCEG: plantio convencional:escarificador mais grade niveladora; PCAG: plantio convencional: arado de discos mais grade niveladora. ${ }^{(2)}$ Médias com letras distintas na coluna diferem pelo teste de Duncan a 5\%. ${ }^{\text {ns }}$ Teste $\mathrm{F}$ não-significativo a 5\% de significância. * Teste $\mathrm{F}$ significativo a 5 \% de significância.

em relação à dos sistemas de menor mobilização do solo(PDC, PDSD ePDV). Considerando otratamento PCAG $\left(2,19 \mathrm{Mg} \mathrm{ha}^{-1}\right)$, verificou-sequea produtividade correspondeu a um acrésci mo de 17,81 \% em relação à produtividade média obtida pelos sistemas de manejo PDC, PDSD e PDV (1,80 $\left.\mathrm{Mg} \mathrm{ha}^{-1}\right)$.

Esse comportamento mais favorável ao tratamento que recebeu aração e gradagem também pode estar associado a algum efeito na melhoria do equilíbrio imobilização/mineralização pela incorporação dos restos culturais da cultura que antecede o trigo, neste caso o milho, visto que o estado estrutural do solo do tratamento PCGA é semel hante ao do PCE G.

As produções acumuladas, nos cinco sistemas de manejo do solo, não diferiram entre si. A percentagem total relativa apresentou diferenças máximas de produção de 2,7 pontos percentuais entre os sistemas de manejo, evidenciando um rendimento de grãos semel hante ao longo dos três anos avaliados. No entanto, alguns trabalhos mostram que os rendimentos de grãos de soja e milho foram maiores nos sistemas com uso de escarificação em relação ao sistema plantio direto. Na região Oeste do Paraná, em um Latossolo roxo distrófico, Bertol \& Fischer (1997) verificaram que o preparo do solo por meio de um escarificador com rolo destorroador proporcionou maior rendimento de grãos de soja em relação aos demais tratamentos, incluindo o sistema plantio direto. Em Cruz Alta (RS), Secco (1994), avaliando o desempenho operacional de escarificadores em Latossolo Vermelho distrófico sob sistema plantio direto, constatou que a produtividade da cultura do milho foi superior no tratamento com escarificação em relação ao tratamento que permaneceu sob sistema plantio direto. Esse autor atribuiu a maior produtividade obtida nas parcelas escarificadas às mel hores condições de espaço poroso do solo.
Apesar de existirem resultados contraditórios, principalmente com relação ao uso da escarificação em solos cultivados no sistema plantio direto, é de suma importância considerar o histórico do sistema de produção. Vários trabalhos, semel hantes a este, que associam o plantio direto a sistemas de culturas com alta adição de resíduos culturais, têm mostrado efeitos benéficos ao estado estrutural do solo, em especial na melhoria do espaço poroso do solo no sistema plantio direto (Albuquerque et al., 1995; Campos et al., 1995).

Com base nisto, os resultados do trabalho mostram não haver necessidade de mobilizar o solo sob sistema plantio direto a cada cultivo/ano (PDV) ou a cada três anos (PDSD), quando comparado ao tratamento plantio direto contínuo (PDC), em cinco anos consecutivos de cultivo nesses sistemas.

\section{CONCLUSÕES}

1. A densidade do solo apresentou valor superior nos tratamentos que sofreram menor mobilização do solo (PDC e PDSD), enquanto a porosidade total ea macroporosi dade apresentaram comportamento inverso.

2. À exceção do PDV, os valores de densidade, por osidade total e macroporos nos demais sistemas de manejo do solo, nos três anos consecutivos e nas três profundidades avaliadas, permaneceram praticamente constantes, não indicando tendência de adensamento no tempo.

3. A produtividade das culturas da soja e milho não diferiram significativamente entre os sistemas de manejo utilizados, indicando que para essas culturas mudanças no estado estrutural do sol o não comprometeram sua produtividade. 
4. A cultura do trigo mostrou-se sensível ao estado estrutural do solo, com os sistemas de manejo do solo com maior mobilização (PCAG) proporcionando condições mais adequadas a esta cultura.

5. Segundo os resultados encontrados, a mobilização do solo a cada ano ou a cada três anos nas áreas conduzidas sob o sistema plantio direto não influiu na produção das culturas e não alterou os atributos.

\section{LITE RATURA CITADA}

ALBUQUERQUE, J.A.; REINERT, D.J .; FIORIN, J .E.; RUEDELL, J .; PETRERE, C. \& FONTINELLI, F. Rotação de culturas e sistemas de manejo do solo: efeito sobre a forma da estrutura do solo ao final de sete anos. R. Bras. Ci. Solo, 19:115-119, 1995.

CAMPOS, B.C.; REINERT, D.J .; NICOLODI, R.; RUEDELL, J . $\&$ PETRERE, C. Estabilidade estrutural de um latossolo vermelho-escuro distrófico após sete anos de rotação de culturas e sistemas de manejo do solo. R. Bras. Ci. Solo, 19:121-126, 1995.

EMPRESA BRASILEIRA DE PESQUISA AGROPECUÁRIA EMBRAPA. Centro Nacional de Pesquisa do Solo.Sistema brasileiro de classificação de solos. Brasília, 1999. 412p.

BERTOL, O.J . \& FISCHER, I.I. Semeadura direta versus sistemas de preparo reduzido: efeito na cobertura do solo e no rendimento da cultura da soja. Eng. Agríc., 17:87-96, 1997.
FERNANDEZ, E.M.; CRUSCIOL, C.C.C. \& THIMOTEO, C..M.S. Matéria seca e nutrição da soja em razão da compactação do solo e adubação fosfatada. Científica, 23:117-132, 1995.

RAGHAVAN, G.S.V.; MCKYES, E. \& CHASSÊ, M. Effect of wheel slip on soil compaction. J. Agric. Eng. Res., 22:7983, 1977.

SECCO, D. Eficiência e efeito residual de escarificadores em Latossolo Vermel ho-Escuro sob plantio direto. Santa Maria, Universidade Federal de Santa Maria, 1994. 76p. (Tese de Mestrado)

SIDIRAS, N.; VIEIRA, S.R. \& ROTH, C.H. Determinação de algumas características físicas de um latossolo roxo distrófico sob plantio direto e preparo convencional. R. Bras. Ci. Solo, 8:265-68, 1984.

STOLZY, L.H. Soil atmosphere. In: CARSON, E.W., ed. The plant root and its enviroment. Charlotlesville, University Press of Virginia, 1974. p.335-361.

STONE, L.F. \& SILVEIRA, P.M. Efeitos do sistema de preparo e da rotação de culturas na porosidade e densidade do sol o. R. Bras. Ci. Solo, 25:395-401, 2001.

TAVARES FILHO, J .; BARBOSA, G. M. C.; GUIMARÃES, M.F . \& FONSECA, I.C.B. Resistência do solo à penetração e desenvol vimento do sistema radicular do mil ho (Zea mays) sob diferentes sistemas de manejo em um Latossolo Roxo. R. Bras. Ci. Solo, 25: 725-730, 2001

TAYLOR, N.W. Root behavior as affected by soil structure and strenght. In: CARSON, E.W., ed. The plant root and its enviroment. Charlotesville, University Press of Virginia, 1974. p.271-291. 